\title{
História da América Latina: inserção internacional e dominação externa
}

\section{Historia de América Latina: inserción internacional y dominación externa}

\section{Latin-America History: international insertion and foreign domination}

\author{
Raphael Lobo Duarte Batista Teixeira ${ }^{1}$
}

\begin{abstract}
Resumo
O sistema mundial tal qual conhecemos hoje, tem em sua gênese o capitalismo colonial/moderno e eurocentrado, padrão de poder este que foi conformado junto a uma constelação de países: alguns centrais e outros satélites. A crença liberal promete que o mercado competitivo, por si só, possa ser inclusivo, gerando crescimento econômico com equidade. Entretanto, tais ideologias comentem o erro crasso de não analisar a particularidade da América Latina dentro desse complexo. O efeito natural do dinamismo do livre mercado, jamais dará conta de resolver os problemas do subdesenvolvimento e da dependência, ao contrário, o modo de produção capitalista tende a cristalizar essas determinações e utiliza-las em seu benefício como forma de acumulação. O objetivo deste artigo é estabelecer um breve apanhado sobre a História da América Latina, sua inserção Internacional, passando pela sistemática divisão internacional e racial do trabalho e as formas de dominação externa.
\end{abstract}

Palavras-chave: América Latina; Inserção; capitalismo mundial.

\section{Resumen}

El sistema mundial tal que conocemos hoy, tiene en su génesis el capitalismo colonial / moderno y eurocentrado, patrón de poder éste que fue conformado junto a una constelación de países: algunos centrales y otros satélites. La creencia liberal promete que el mercado competitivo, por sí solo, pueda ser inclusivo, generando crecimiento económico con equidad. Sin embargo, tales ideologías comenta el error craso de no analizar la particularidad de América Latina dentro de ese complejo. El efecto natural del dinamismo del libre mercado, jamás dará cuenta de resolver los problemas del subdesarrollo y de la dependencia, al contrario, el modo de producción capitalista tiende a cristalizar esas determinaciones y utilizarlas en su beneficio como forma de acumulación. El objetivo de este artículo es establecer un breve recuento sobre la historia de América Latina, su inserción internacional, pasando por la sistemática división internacional y racial del trabajo y las formas de dominación externa.

Palavras claves: América Latina; la integración; capitalismo mundial.

\begin{abstract}
World's system how we know nowadays has it's genesis in colonial/modern and eurocentered capitalism, this pattern of power was conformed within a big number of countries, some of them in the center, some orbiting the system. The liberal belief promises that competitive market, by itself, may be inclusive, generating economic growth with equality. However, these ideologies take for granted this complex scenario and doesn't analyze Latin-American's particularities. The natural effect "dynamism" in the free market will never solve underdevelopment and dependence's problems, on the opposite, capitalism mode of production tends to crystalize this determinations and use it in it's own behalf for accumulation. The objective of this article is stablish a brief history of Latin-America, the international insertion, and the systematic international and racial division of labor and external domination.
\end{abstract}

Keywords: Latin-America; insertion; world capitalism.

\footnotetext{
${ }^{1}$ Mestrando de pós-graduação em Integração Contemporânea da América Latina - PPGICAL e discente de Ciências Econômicas do Instituto Latino-Americano de Economia, Sociedade e Política - ILAESP da UNILA, a Universidade Federal da Integração Latino Americana. É membro do Grupo de Pesquisa América Latina: Integração e Desenvolvimento - GPAID. E-mail: raphael.teixeira@aluno.unila.edu.br.
} 


\section{Introdução}

A despeito de certa crença liberal ingênua, que intelectuais de visão dualista sustentaram durante longos anos e que inconsciente ou conscientemente ainda se faz presente no meio acadêmico brasileiro e Latino Americano - de que o mercado competitivo e robusto, por si só, possa ser inclusivo, gerando crescimento com equidade e, que nossos países estão se "desenvolvendo" a caminho do que se chama "países desenvolvidos". Olvidam que cumprimos determinada função específica dentro do sistema mundial capitalista, e que nossa dependência, o racismo $^{2}$, a segregação social e a superexploração, absolutamente vai ser eliminada através do corolário natural do dinamismo econômico do livre mercado, pelo contrário, o modo de produção capitalista tende a cristalizar essas contradições a seu benefício e utilizar essas determinações como forma de acumulação.

A ideia permanente de criar choques de modernização, com vias de superação de nosso "atraso", propagados pelos meios de comunicação das classes dominantes é, e tem como pressupostos essa "visão dualista" do "arcaico" e do "moderno"3.

O impasse que com frequência apresenta-se ao pesquisador interessado no estudo das ciências sociais na América Latina, e que provavelmente não existe desafio mais difícil, é o da classificação dos fenômenos sociais. Construir uma tipologia válida e útil para a análise científica que expressam a nossa realidade concreta.

Neste artigo, ganham destaque as ideias de Aníbal Quijano, Florestan Fernandes, Darcy Ribeiro e Celso furtado.

Da análise feita, pode-se concluir que por mais forte, intensa e violenta que possam ser as ondas com finalidade de modernizar os países Latino-Americanos, essas sempre terminaram não só com a manutenção da dependência, como também seu aprofundamento.

O subdesenvolvimento e a dependência são partes de uma totalidade chamada sistema-mundo capitalista, de modo que não estamos no centro desse conjunto, mas na periferia.

\footnotetext{
2 "El hecho es que ya desde el comienzo mismo de América, los futuros europeos asociaron el trabajo no pagado o no-asalariado con las razas dominadas, porque eran razas inferiores".(QUIJANO, 200, pg. 207)

${ }^{3} \mathrm{Na}$ década de 50, o francês Jacques Lambert e Gino Germani tiveram grande repercussão no Brasil, especialmente o primeiro, que escreveu Os Dois Brasis.
} 
A inserção da região Latino Americana como dependente e periférica se dá pari passu com a conformação da hegemonia Inglesa na Europa, com a gênese da grande indústria moderna.

\section{Há uma América Latina?}

Essa pergunta foi eternizada pelo antropólogo brasileiro, Darcy Ribeiro, em um ensaio realizado no México em 1976. Para o ilustre pensador, não há dúvida que sim! Para Ribeiro (1986) a América Latina existe a partir de uma utopia, com gênese, na sua unidade continental.

Não obstante, essa unidade geográfica, não se reflete em uma unidade dos povos latino-americanos, mesmo considerando certo grau de conformidade, linguística e cultural. A explicação para essa desintegração das sociedades tem como uma de suas causas centrais, o processo de ocupação ibérica. Visto que, somos um "conjunto de povos internacionalmente constituídos por atos e vontades alheios a eles mesmos" (RIBEIRO, 1986, p. 77).

Cardoso e Brignoli no livro História Econômica da América Latina (1984) destaca, que o aspecto singular do que viria a se converter em América Latina, está na herança do que foi a dominação da América indígena e África negra. A concepção de raça em um sentido moderno, foi gestada a partir daí, como nos lembra de Quijano (2000), a ideia de raça no tem história conhecida antes de América,

En América, la idea de raza fue un modo de otorgar legitimidad a las relaciones de dominación impuestas por la conquista. La posterior constitución de Europa como nueva id-entidad después de América y la expansión del colonialismo europeo sobre el resto del mundo, llevaron a la elaboración de la perspectiva eurocéntrica de conocimiento y con ella a la elaboración teórica de la idea de raza como naturalización de esas relaciones coloniales de dominación entre europeos y noeuropeos (QUIJANO, 2000, pg. 203).

Por este ângulo (RIBEIRO, 1986), a unicidade basilar da região desenrola-se, do processo civilizatório que nos moldou - o caos de uma destruição gigantesca. "O que hoje conhecemos pelo nome de América Latina era reconhecida pelos povos que aqui viviam a partir de outras designações. Abya-Yala, Tawantinsuyu e Anahuac são algumas delas" (GONÇALVES; QUENTAL, 2013, p. 2).

A população indígena no continente segundo Darcy Ribeiro (1986) superava a casa dos cem milhões, em 1500. Três séculos depois, em 1825, já se tinha menos de dez milhões. Assim, é que,

a metrópole colonialista teve um projeto explícito e metas muito claras, atuando da forma mais despótica. Conseguiu, quase de imediato, subjugar a sociedade preexistente, paralisar a cultura original e converter a população em uma força de trabalho submissa (RIBEIRO, 1986, p. 19). 


\section{Tipologias}

O impasse que com frequência apresenta-se ao pesquisador interessado no estudo das ciências Sociais na América latina e que provavelmente não existe desafio mais difícil é o da classificação dos fenômenos sociais. Construir uma tipologia válida para a análise científica e útil que expressam a nossa realidade concreta.

A resultante de anos de alienação colonial produz, em grande medida, uma incapacidade de examinar diretamente a nossa própria realidade e traçar uma epistemologia expressiva na compreensão de nós mesmos.

Por este ângulo, a alienação terminológica produz erros graves de análise o que, por conseguinte, ocasionam tácticas e estratégicas também equivocadas: conduta política errônea seja de governos ou de forças populares.

Grande parte desses estudos resulta de esquemas prontos, adaptadas de outras realidades, citando o caso, as categorias como "burguesia", "proletariado", "fascismo", "populista", entre outros.

A título de paradigma, Darcy Ribeiro (1982) faz críticas a alguns pensadores marxistas que dissertaram sobre a questão indígena,

Os fanáticos das lutas de classe - esquecidos de que a estratificação social é coisa recente, muitíssimo mais nova que as entidades étnicas, e de que é até provável que as classes desapareçam antes das nacionalidades - teimando em negar a identidade desses indigenatos como povos oprimidos, contribuíram ponderavelmente para que eles continuassem sendo oprimidos (RIBEIRO, 1982, p . 73)

Neste anseio do intelectual latino-americano em tipificar corretamente a complexidade de fusões, mudanças, modelos culturais aqui em jogo, é que neste artigo, abordaremos as teses defendidas por dois intelectuais brasileiros: Darcy Ribeiro e Celso Furtado. Que apesar de terem contribuído, cada uma a sua maneira, no governo nacionalpopulista de João Goulart (1961-1964) não se relacionaram a nível acadêmico. Contudo, pode-se dizer que as teorias possuem certo grau de complementaridade.

\subsection{Configurações Histórico-culturais}

Para Ribeiro (1986), a Américas se diferencia, por seu processo de formação, que podem ser divididos em três categorias: povos testemunho, povos novos e, por último, povos transplantados. O autor trabalha esses conceitos detalhadamente no seu livro As Américas e a Civilização (1970), que alcança significa importância, pois é uma tentativa de contar a história da América Latina através dos povos, com uma tipologia própria, tentando fugir do 
padrão cientificista racista de classificação social. Fazendo uma clara distinção entre a Nuestra América, Latina, e a América rica, a Anglo-América.

Esse esforço tem como propósito também explicar as causas do subdesenvolvimento e da dependência da América pobre. Talvez a procura por essa resposta, era a grande inquietude das ciências sociais na década de 60 e $70^{4}$.

A tipologia apresentada por Darcy Ribeiro é um estudo que visa integração orgânica da realidade dos povos latinos americanos. Cada categoria da tipologia de Ribeiro (1977) está selecionada em três grupos, que recebe o nome de Tipologia Étnica-nacional, por sua vez separadas em europeus e extra-europeus. Nesses últimos se encontram as três categorias ${ }^{5}$ já mencionadas, entretanto existe outra a de povos emergentes. Todavia esses não estão presentes na América latina.

Sob essa perspectiva, os povos testemunhos seriam fruto do choque de altas civilizações, que se encontravam na região antes de 1942, com a expansão mercantil europeia. Os descendentes de grandes civilizações como Maias, Incas e Aztecas, que mesmo sofrendo forte europeização não conseguiram se diluir totalmente.

Conforme explica que,

Cada um destes povos testemunho experimentou enormes vicissitudes e sofre profunda europeização. Insuficiente, porém, para fundir num ente etnicamente unificado toda a população. Vivem o drama da ambiguidade de povos situados entre dois mundos culturais contrapostos, sem poder optar por nenhum deles. Já não são índios. Jamais serão europeus (RIBEIRO, 1986, p.126).

Já a categoria de povos novos, é oriunda da engenharia de colonização. Da mistura dos europeus desterrados, que depois virou criollos gerente da empresa colonial, ora pelos nativos da terra e polos negros trazidos da África, recebendo heranças essenciais desses dois últimos.

Dessa maneira,

Os povos novos, feitos pela confluência de índios tribais, negros escravos e brancos ibéricos aliciados nas plantações tropicais, para exploração de produtos florestais ou de minas e metais preciosos, que deram a um ente étnico inteiramente novo, profundamente diferenciado de suas três matrizes e que ainda anda em busca de sua identidade (RIBEIRO, 1986, p 86).

\footnotetext{
${ }^{4}$ Rui mauro Marini faz uma bela análise desse período no artigo "La crisis teórica. América Latina: integración y democracia, 1993".

${ }^{5}$ povos testemunho, povos novos e, por último, povos transplantados.
} 
Os povos transplantados da América Latina são resultantes de um empreendimento da elite criolla. Projeto de uma intensiva imigração com a intensão de "branqueamento".

Segundo Ribeiro, os povos transplantados seriam,

Constituídos pela expansão de nações europeias sobre territórios de ultramar e, onde sem se misturarem com a população local, reconstruíram sua paisagem e retomaram suas formas originais de vida. A seguir, se desenvolveram culturalmente dentro de linhas paralelas e similares às da metrópole, como povos brancos de ultramar (1986, p. 126).

\subsection{As economias exportadora de matérias primas}

No sexto capitulo da obra A economia Latino-americana: Formação e Problemas Contemporâneos (1976). Celso furtado vai esboçar a sua tipologia baseada nas economias exportadoras de matérias primas. Que se encaixa perfeitamente na de povos de Darcy Ribeiro.

Furtado também irá dividir sua tipologia em três seções: as economias exportadoras de produtos agrícolas de clima temperado, economias exportadoras de produtos agrícolas tropicais, e por fim, economias exportadoras de produtos minerais.

De acordo com Furtado (2007) as economias de clima temperado seriam o Uruguai e Argentina, onde se deu um uso extensivo da terra com a intensão de disputar com a própria produção interna dos países em fase do processo de industrialização. Uma terra de boa qualidade, que acomodava uma oligarquia que se sentia herdeira da civilização europeia ocidental.

As economias de clima tropical estariam no Brasil, Colômbia, Equador, América central, Caribe e parte de México e Venezuela. Esses países se especializaram desde sua inserção no mercado mundial até meados de suas independências, em produtos tidos como novos $^{6}$.

Segundo Furtado (2007), esses países se inseriram no comercio mundial através da competição com outras regiões coloniais, diferente das economias de clima temperado que competiam com as zonas centrais.

Os baixos salário, de uma população ex-escrava, baixa técnica agrícola, superpopulação e um mercado interno muito debilitado, é uma das singularidades dessa categoria. Aníbal Quijano (2000) nos permite uma compreensão mais ampla desta problemática,

El hecho es que ya desde el comienzo mismo de América, los futuros europeos asociaron el trabajo no pagado o no-asalariado con las razas dominadas, porque eran razas inferiores[...] La inferioridad racial de los colonizados implicaba que no eran dignos del pago de salario. (pg. 207).

\footnotetext{
${ }^{6}$ Cacau, banana, açúcar, café e etc...
} 
No que diz respeito às economias de produtos minerais, Furtado (2007) enquadra os países como a Venezuela, México, Peru, Chile e Bolívia. São regiões que tiveram um acentuado processo de espoliação nos estágios coloniais e posteriormente, na fase de industrialização dos países centrais, contou com forte ingresso de capital estrangeiro, que limitou profundamente a expansão de infraestrutura e internacionalização de suas cadeias produtivas.

\subsection{A inserção no sistema Internacional e a primeira dominação externa na América Latina}

Para lograr uma análise da sociedade brasileira buscando o máximo de precisão, se faz necessário um recuo no tempo, no modo de como a América Latina é inserida no sistema mundial capitalista no início do século XVI. Pois como escreveu Caio Prado Jr (1978, p. 18), "o Brasil ainda se acha intimamente entrelaçado com o seu passado. E não pode por isso, ser entendido senão na perspectiva e à luz deste passado".

O eixo central que perpassa por toda a nossa formação, é o dos tipos de dominação externas na América Latina.

Segundo Florestan Fernandes (1975), o colonialismo sistemático e organizado, empreendido por Espanha e Portugal, que resultou na conquista do continente LatinoAmericano, é resultante também, da evolução do modo de produção capitalista.

O antigo sistema colonial foi igualmente causador da conformação de uma estrutura de classes que, engendrou o espírito dominante da nossa burguesia. Sendo essa aristocrática e oligárquica. Uma plutocracia que concentra a riqueza, o prestígio social e o poder. As instituições, carregam consigo, da mesma forma, o empreendimento colonial.

Segundo Fernandes,

Em termos jurídicos, a legitimidade de dominação tinha um duplo fundamento, legal e político, Os colonizadores eram submetidos à vontade e ao poder das Coroas de Espanha e Portugal, às quais deviam, como vassalos, obediência e lealdade (1975, p. 13).

O primeiro tipo de dominação externa, é a existência de uma ordem social onde os interesses externos e internos são conformados, desenvolvido e reforçados. Deixando de fora dessa sociedade colonial, os negros, escravos e os indígenas.

Uma estratificação social, que submetia a grande massa da população a altos níveis de exploração e violência. A estrutura sócio-econômica básica da sociedade brasileira, segundo Caio Prado Jr (1978, p. 36), “o europeu que vem especular, realizar um negócio, 
fazendo-se para isto o empresário, dirigente e administrador da empresa destinada a fornecer os produtos oferecidos pelo território ocupado".

A constituição do modo de produção capitalista, tem na sua gênese, qualquer que seja a via pela qual se processe, uma fase originária, o processo de acumulação primitiva de capital, que nas palavras de Jacob Gorender (1982, p. 8), "trata-se de uma acumulação do capital realizada por mecanismos ainda não essencialmente capitalistas, não se baseado portanto, na produção de mais-valia mediante a exploração do trabalho assalariado livre”.

No caso específico, brasileiro, ter-se-á o pressuposto de que a acumulação originária se processou no ramo do escravismo colonial e na produção colonial do açúcar. Entretanto, essa acumulação primitiva ou originária, tem pouca retenção dos excedentes gerados.

De acordo com Fernandes (1975), de 12\% a 18\% em média, era o lucro bruto dos dirigentes do negócio. O grosso do excedente ficava com a Coroa e os mercadores que faziam a travessia e obtinham o lucro do mercado consumidor final.

A produção de mercadorias exportáveis, livre do controle do antigo sistema colonial executado por potências centrais em declínio, foi o motor dos movimentos de emancipação política.

\subsubsection{A Dominação neocolonial}

Nos anos de 1810-1820 do século XVIII se inicia a independência formal dos países latino-americanos, época que é marcada pelas guerras napoleônicas e com enfraquecimento dos países ibéricos que ocasionou transformações nas estruturas coloniais. Para acentuar tais mudanças, podemos citar a destruição da armada espanhola em 1958 e da colonização econômica do desmonte da manufatura de Portugal através de uma série de acordos comerciais que culminaram no tratado de Methuen em 1703 (FRANK, 1973). A Inglaterra eliminou a possibilidade dos países ibéricos de participarem do processo do desenvolvimento do capitalismo mundial.

Daí surge o segundo tipo de dominação externa, nas palavras de palavras de Fernandes,

As nações européias, que conquistaram o controle dos negócios de exportação e de importação na América Latina (a Inglaterra em particular), estavam inicialmente mais interessadas no comércio que na produção local. Durante quase quatro ou cinco décadas - do fim do século XVIII até as primeiras três ou quatro do século XIX - esses países ocuparam o vácuo econômico deixado pela desagregação do antigo sistema colonial, ao invés de exercerem o papel de um "poder imperial" (1975, p. 15).

A institucionalização de um modelo de economia e sociedade voltados para o fim basilar de servir ao comércio internacional e abastecer os mercados externos, sem integrar-se 
com o mercado consumidor e a massa da população, consolida uma estratificação social que não oferece condições favoráveis para a formação de um mercado interno e a demanda efetiva, quase em sua totalidade composta por um setor exclusivo de alto padrão de consumo, que não terá suas necessidades atendidas pela produção local, sendo estas preenchidas pelas importações de produtos manufaturados, em especial artigos de luxo.

Em face deste cenário, o período neocolonial é nada mais que uma dominação externa indireta. É a disseminação de agências bancárias e comerciais, e da monopolização dos mercados.

Em vista de sua formação econômico-social, as elites locais "preferiram escolher um papel econômico secundário e dependente, aceitando como vantagem a perpetuação das estruturas econômicas construídas sob o antigo sistema “(FERNANDES, 1975, p. 16).

\subsubsection{Revolução Industrial e a terceira dominação externa}

O neocolonialismo foi um elemento de grande impulso da revolução industrial, o comércio triangular foi parte da acumulação de capital nos países centrais. A acumulação primitiva de capital insuficiente na América latina, é resultado de uma extração excedente, canalizado para o desenvolvimento do capitalismo industrial europeu.

Dessa maneira,

O impacto do descobrimento das Américas, conquista da índia e a transformação da África numa reserva de escravos configuraria o ápice da produção capitalista, fundamentais para a acumulação. Essa riqueza promoveu competições e guerras entre nações Europeias. Os tesouros espoliados fora da Europa diretamente mediante saqueio, a escravização e o latrocínio refluíram à metrópole e lá se transformavam em capital (MARX, 2013, p. 823).

O processos de independências políticas nos países da América Latina, coincidem com o advento da revolução industrial e emerge dela, tendo a Inglaterra como país hegemônico, apresentando novas formas de articulações entre o centro e a periferia do sistema.

Quanto a esse aspecto, Florestan Fernandes diz que:

As influências externas atingiram todas as esferas da economia, da sociedade e da cultura, não apenas através da incorporação maciça e direta de algumas fases dos processos básicos de crescimento econômico e de desenvolvimento sociocultural,. Assim, a dominação externa tornou-se imperialista, e o capitalismo dependente surgiu como uma realidade da América Latina (1975, p. 16).

Com esse diagnóstico, traça-se um percurso de suma importância para a compreensão da revolução burguesa no brasil. Roteiro este iniciado na primeira dominação externa do 
antigo sistema colonial, aprimorado pelo neocolonialismo e que vai se consolidar no caráter subordinado do modo de produção capitalista, no quarto padrão de dominação externa.

\title{
3.3.3. O Imperialismo total
}

O quarto tipo de dominação externa, para usar uma categoria do Florestan, representa a fase do Imperialismo total. O que caracteriza essa tipologia de dominação externa, na perspectiva do autor, é que o atraso e a dependência não se devem apenas a fatores meramente externos, impostos às economias Latino Americanas mas, deve-se também a fatores internos, institucionalizados.

A aliança burguesia-latifúndio-imperialista em harmonia com a expansão das grandes empresas corporativas da nova potência hegemônica, no caso os Estados Unidos, é o que difere o imperialismo total do tipo de imperialismo restrito, presente nos outros padrões de dominação externa.

Segundo Fernandes (1975), esta peculiaridade também se dá por,

\begin{abstract}
O traço específico do imperialismo total consiste no fato de que ele organiza a dominação externa a partir de dentro e em todos os níveis da ordem social, desde o controle da natalidade, a comunicação de massa e o consumo de massa, até a educação, a transplantação maciça de tecnologia ou de instituições sociais, a modernização da infra, e da superestrutura, os expedientes financeiros ou do capital, o eixo vital da política nacional e etc (1975, p. 18).
\end{abstract}

A quarta fase de dominação, demonstra a natureza da classe burguesa de capitalismo periférico - não possui motivação de vestir um projeto nacional, pois internamente colabora com o desenvolvimento. "Como nos outros três períodos, a implementação de mudanças é realizada por um contingente estrangeiro, transplantação maciça de tecnologia e de instituições, suprimento externo de capital e de controle financeiro" (FERNANDES, 1975, p. 19).

Esse novo modo de acumulação capitalista é agressivo, voraz, desmistificador de qualquer sonho nacionalista burguês. É em si, nas palavras de Florestan (1975), destrutivo para o desenvolvimento dos países latino-americanos.

Assim, diante desse quadro sentencial, é fundamental fazer o apanhado do processo de Revolução burguesa no Brasil. De modo a compreender como a erupção do moderno imperialismo foi aclamado por nossas elites, utilizando da cooperação monopólica e subordinando a pequena burguesia ou a parcela de uma elite nacional à incorporação dependente mais eficaz ao espaço econômico do que julgam ser sócio culturalmente moderno e eficaz, no caso, a incorporação às multinacionais, sobretudo dos Estados Unidos. 


\section{Considerações Finais}

Como foi possível verificar no decorrer deste trabalho, a História da América Latina envolve um conjunto de complexos de determinações que inviabiliza qualquer projeto liberal com suposta emancipação.

A teoria tradicional da modernização, parte do pressuposto que os elementos arcaicos são um impeditivo para determinada região ascender ao desenvolvimento. Essa admiração integral pelo progresso da modernidade, ainda presente nas ciências sociais, mistifica e colide com a configuração do sistema mundial capitalista.

Os padrões de dominação externa, tão bem aclarados por Florestan Fernandes, nos possibilita observar que a América Latina cristalizou um padrão de funcionamento que permite pouca, ou talvez nenhuma, mudança nas estruturas. O padrão de funcionamento da luta de classes na América Latina perpassa a questão racional - há uma divisão internacional, todavia, há uma divisão racial do trabalho.

A América Latina possui um regime típico de sociedades com segregação social e racial, que teve sua gênese ainda no primeiro padrão de dominação - a inferioridade racial dos colonizados resultava na sua superexploração, isto é, não eram dignos de receber um salário minimamente digno. Desde muito cedo a região tem a sua força de trabalho engendrada num complexo de transferência de valor para mercados estranhos.

Fica claro que dentro deste sistema, não há outro horizonte possível - o capitalismo periférico depende da continuidade dessas determinações, não dispõe de bases estruturais para conceder, ou ceder o inverso do que proclama a doutrina liberal.

A ideologia da modernização encobre os padrões de dominação que tendem a se eternizar.

\section{Referências Bibliográficas}

CARDOSO, Ciro Flamarion; BRIGNOLI, Héctor Pérez. História Econômica da América Latina. 3. ed. Niterói: Graal, 1988.

FERNANDES, Florestan. CAPITALISMO DEPENDENTE: e classes sociais na América Latina. 2. ed. Rio de Janeiro: Zahar Editores, 1972.

FURTADO, Celso. A economia latino-americana: Formação histórica e problemas contemporâneos. 4. ed. São Paulo: Companhia das Letras, 2007. 494 p. 
MARX, Karl. O capital: crítica da economia política: Livro I: o processo de produção do capital. [ tradução: Rubens Enderle]. São Paulo: Boitempo, 2013. (Marx-Engels).

QUIJANO, Aníbal. Colonialidad del poder, cultura y conocimiento en América Latina. Dispositio, v. 24, n. 51, p. 137-148, 1999.

QUIJANO, Aníbal. Colonialidad del poder, eurocentrismo y América Latina. 2000.

RIBEIRO, Darcy. América Latina: A Pátria Grande. Rio de Janeiro: Editora Guanabara, 1986. $154 \mathrm{p}$.

RIBEIRO, Darcy. Processo de formação e causas do desenvolvimento desigual dos povos americano. 2. ed. São Paulo: Civilização Brasileira, 1970. 660 p.

\section{Bibliografia Consultada}

FERNANDES, Florestan. Poder e Contrapoder na América Latina. 2. ed. São Paulo:

Expressão Popular, 2015. 148 p.

FERNANDES, Florestan. Sociedade de classes e subdesenvolvimento. 5. ed. São Paulo:

Global, 2008. 253 p.

FRANK, André Gunder. El desarrollo del subdesarrollo. Universidad Nacional de Colombia. Facultad de Ciencias Humanas. Departamento de Economa', 1966.

RIBEIRO, Darcy. O dilema da América Latina: estruturas de poder e forças insurgentes. Ed. Vozes, 1978. 